\title{
A Região Metropolitana como recorte espacial para estudos sobre o agronegócio: questões de método e metodologia
}

\section{The Metropolitan Region as a spatial feature for studies on agribusiness: questions of method and methodology}

\section{La région métropolitaine comme découpe spatial pour les études sur l'agrobusiness: questions de méthode et de méthodologie}

\author{
(iD) Denise Elias \\ Universidade Estadual do Ceará - Fortaleza - Ceará - Brasil \\ deniseliasgeo@gmail.com
}

Resumo: O estado do Ceará assumiu um novo papel na divisão social e territorial do trabalho nas três últimas décadas. É significativa sua reestruturação econômica e territorial frente às exigências do neoliberalismo e da produção flexível, com objetivos claros de inserção na produção e no consumo globalizados. Este artigo apresenta questões de método e de metodologia de pesquisa sobre o agronegócio na Região Metropolitana de Fortaleza. Para orientar o desenvolvimento deste estudo, algumas hipóteses foram trabalhadas, a saber: 1) o agronegócio soma uma grande quantidade de atividades econômicas na Região Metropolitana de Fortaleza; 2) a cidade de Fortaleza é o principal centro de gestão do agronegócio no Ceará e 3) o agronegócio compõe o circuito superior da economia urbana de algumas cidades cearenses, sendo na de Fortaleza onde tal fenômeno é mais presente e complexo. Como metodologia, utilizamos um recurso que chamamos de matriz metodológica, que tem por objetivo organizar de forma encadeada os procedimentos de método e metodologia para a consecução da 
pesquisa e, como recorte temporal, adotamos a década de 1990 até o presente. Concluímos que a região metropolitana é um recorte espacial importante para os estudos sobre o agronegócio e que o estudo desse agronegócio é estrutural para a interpretação da própria economia política de Fortaleza e de sua região metropolitana.

Palavras-chave: Agronegócio. Região Metropolitana. Fortaleza. Ceará

Abstract. The state of Ceará has assumed a new role in the social and territorial division of labor in the past three decades. Its economic and territorial restructuring is significant in the face of demands of neoliberalism and flexible production, with clear objectives of insertion in globalized production and consumption. This article presents questions of method and research methodology about the agribusiness in the Metropolitan Region of Fortaleza. To guide the development of this study, some hypotheses were worked out, namely: 1) agribusiness encompasses a large amount of economic activities in the Metropolitan Region of Fortaleza; 2) the city of Fortaleza is the main agribusiness management center in Ceará and 3) agribusiness composes the urban economy upper circuit of some cities in Ceará, being Fortaleza the place where such phenomenon is more active and complex. We use a methodological matrix, aiming to organize method and methodology procedures for conducting the research in a linked way and, as a temporal cut, we adopted the 1990s to the present. We conclude that metropolitan region is an important spatial cut for studies about agribusiness and that the study of this agribusiness is structural for the political economy interpretation of the city of Fortaleza and its Metropolitan Region.

Key-words: Agribusiness. Metropolitan Region. Fortaleza. Ceará

Résumé : L'état du Ceará a assumé un nouveau rôle dans la division sociale et territoriale du travail au cours des trois dernières décennies. Sa restructuration économique et territoriale sont significatives face aux exigences du néolibéralisme et de la production flexible, avec des objectifs clairs d'insertion dans la production et la consommation mondialisées. Cet article présente des questions de méthode et de méthodologie de 
recherche sur l'agrobusiness dans la Région Métropolitaine de Fortaleza. Pour guider le développement de cette étude, quelques hypothèses ont été travaillés, à savoir: 1) l'agrobusiness représente une part importante des activités économiques dans la Région Métropolitaine de Fortaleza; 2) la ville de Fortaleza est le principal centre de gestion du agrobusiness du Ceará; 3) l'agrobusiness constitue le circuit supérieur de l'économie urbaine de certaines villes du Ceará, à Fortaleza où ce phénomène est plus présent et plus complexe. En tant que méthodologie, nous utilisons une ressource que nous appelons la matrice méthodologique, qui vise à organiser de manière liée les procédures le méthode et méthodologie pour l'exécution de la recherche et, comme coupure de temps, nous avons adopté les années 1990 jusqu'à nos jours. Nous concluons que la région métropolitaine est une zone spatiale importante pour les études sur l'agrobusiness et que l'étude de cette agrobusiness est structurelle pour l'interprétation de l'économie politique de Fortaleza et de sa région métropolitaine.

Mots clés: Agrobusiness. Région métropolitaine. Fortaleza. Ceará 
A Região Metropolitana como recorte espacial para estudos sobre o agronegócio... Denise Elias

\section{Introdução ${ }^{1}$}

O agronegócio globalizado é um conjunto de atividades que se dão em rede, de forma totalmente interligada e multiescalar, que inclui: produção agropecuária; atividades industriais de transformação, beneficiamento e modificação desta agropecuária, comumente chamadas de agroindústria; indústrias de máquinas agrícolas, agrotóxicos, produtos veterinários; serviços de pesquisa agropecuária, finanças, extensão, logística, ensino tecnológico, marketing, assistência técnica, comércio exterior; comércios de fertilizantes, sementes melhoradas, peças para irrigação; redes de supermercados; fundos de investimentos; redes de poder (tal como a poderosa bancada ruralista que atua no Congresso Nacional), entre outras (ELIAS, 2003a, 2013b, 2017a).

Neste contexto, é evidente que os estudos sobre o agronegócio não estão limitados à agropecuária, mas precisam ser intersetoriais e interescalares, sob pena de terem sua compreensão inviabilizada. Da mesma forma, não se restringem ao campo. A economia e o espaço urbanos estão no âmago do problema de pesquisa quando se quer efetivamente compreendê-lo.

Este artigo tem por objetivo apresentar questões de método e de metodologia de uma pesquisa em andamento sobre o agronegócio na Região Metropolitana de Fortaleza. Ele dá continuidade às nossas reflexões sobre a importância que a cidade e a economia urbana têm para a difusão do agronegócio no Brasil e a sua influência na expansão da urbanização do país.

Há tempos defendemos a tese de que a cidade tem importância crucial para a economia, a sociedade e o território do agronegócio, ou seja, de que as condições materiais para reprodução do capital do agronegócio também se dão nas cidades. A novidade aqui fica por conta do recorte espacial, qual seja, o de uma região metropolitana, no caso específico da Região Metropolitana de

\footnotetext{
1 Agradecemos ao Conselho Nacional de Desenvolvimento Científico e Tecnológico (CNPq) pelo financiamento da pesquisa que deu origem a este artigo. Da mesma forma, agradecemos ao professor Dr. Renato Pequeno, coordenador do Laboratório de Estudos da Habitação (LEHAB) da Universidade Federal do Ceará (UFC), pela leitura, comentários e sugestões.
} 
A Região Metropolitana como recorte espacial para estudos sobre o agronegócio... Denise Elias

Fortaleza (RMF), localizada no estado do Ceará, na Região Nordeste do Brasil. ${ }^{2}$ Além do mais, como recorte temporal, adotamos a década de 1990 até o presente.

O Ceará assumiu um novo papel na divisão social e territorial do trabalho nas três últimas décadas. É significativa sua reestruturação econômica e territorial frente às exigências do neoliberalismo e da produção flexível, com objetivos claros de inserção na produção e no consumo globalizados. Essas reestruturações se manifestam, entre outros, pela difusão do agronegócio globalizado. ${ }^{3}$

Para orientar o desenvolvimento deste estudo, trabalhamos com algumas hipóteses estruturais e complementares, a saber: 1 ) o agronegócio soma uma grande quantidade de atividades econômicas na RMF, sejam elas industriais, comerciais, de serviços e até mesmo agropecuárias em alguns dos 19 municípios que hoje a compõem; 2) a cidade de Fortaleza é o principal centro de gestão do agronegócio no Ceará e 3) o agronegócio compõe o circuito superior da economia urbana de algumas cidades cearenses, sendo na de Fortaleza onde tal fenômeno é mais presente e complexo. ${ }^{4}$

Com a finalidade de organizar de forma encadeada os procedimentos de método e metodologia para a consecução da pesquisa, afora os procedimentos clássicos da metodologia científica, recorremos a um recurso utilizado nos últimos anos que chamamos de matriz metodológica. Esta visa organizar os temas, processos, agentes, variáveis, indicadores e suas respectivas fontes de comprovação associados a uma pesquisa científica.

Além desta introdução, o artigo é composto por quatro seções. Na primeira, fazemos uma síntese sobre a nossa compreensão da cidade como lócus da regulação do agronegócio globalizado. Na segunda, apresentamos os dois dos principais elementos de operacionalização da pesquisa: as questões norteadoras e a ma-

\footnotetext{
2 Muito embora já tenhamos destacado em outros momentos a importância da metrópole para o agronegócio no Brasil, é a primeira vez que temos uma região metropolitana como recorte espacial de uma pesquisa.

3 Sobre o agronegócio globalizado no Ceará, pode ser visto, entre outros, Elias (1999, 2002a, 2002b, 2003b, 2005) e Elias e Pequeno $(2006,2013)$.

4 Para ler sobre os dois circuitos da economia urbana, ver Santos (2004),
} 
A Região Metropolitana como recorte espacial para estudos sobre o agronegócio... Denise Elias

triz metodológica. Na terceira, compartilhamos o detalhamento da matriz em seus elementos de análise. As principais questões de método e as estratégias de operacionalização da pesquisa são abordadas nas duas últimas seções descritas. E, por último, na quarta seção, temos as Considerações Finais.

\section{A cidade como lugar de reprodução do capital do agro- negócio}

A tese de que a cidade tem importância crucial para a economia, a sociedade e o território do agronegócio no Brasil já foi defendida em diferentes momentos. ${ }^{5}$ O agronegócio cria inúmeras novas demandas de produtos e serviços especializados e as cidades são eficazes para satisfazer tais necessidades. Desta forma, uma série de bens e serviços diretamente associados às condições gerais de produção do agronegócio estão na cidade. É na cidade que se dá a gestão do agronegócio, pelas seguintes razões: é onde ocorre a elaboração das normas; se localizam as sedes corporativas dos principais agentes do agronegócio, parte das agroindústrias, as bolsas de valores; reside a maior parte dos trabalhadores, especializados ou não; estão as lojas de sementes geneticamente modificadas, de venda de máquinas agrícolas, as sedes das empresas de aviação agrícola, de consultoria etc.

As cidades são, portanto, importantes pontos e nós dos circuitos espaciais de produção e dos círculos de cooperação (SANTOS, 1986, 1988, 1993) do agronegócio globalizado. O estudo destes circuitos e círculos nos mostra um conjunto de interações espaciais (CORRÊA, 2016) entre campo e cidade e entre cidades de diferentes extratos na rede urbana, assim como entre diferentes regiões do país com o restante do mundo. Isto evidencia tanto a grande capilaridade do agronegócio quanto a necessidade de que os estudos sobre ele tenham caráter multiescalar.

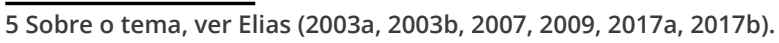


A Região Metropolitana como recorte espacial para estudos sobre o agronegócio... Denise Elias

À medida que a reestruturação produtiva da agropecuária avança, mais se aprofunda a divisão social e territorial do trabalho do agronegócio, mais numerosas e complexas se tornam as relações campo-cidade, mais aumenta o número e o tamanho das aglomerações urbanas próximas aos campos produtivos das principais commodities, promovendo uma mudança do patamar da urbanização brasileira. Várias são as cidades que polarizam regiões produtivas associadas ao agronegócio e que ganharam destaque na rede urbana do Brasil nas últimas três décadas.

Em nossa compreensão, podemos mesmo falar da existência de uma rede de cidades associadas ao agronegócio, composta por pequenas cidades em um de seus extremos e importantes cidades globais do outro.

Pensando na divisão do trabalho entre as cidades dessa rede, grosso modo, poderíamos dizer que as cidades pequenas são os lugares cujo entorno imediato realiza alguma produção agropecuária intensiva e, por vezes, também a produção industrial associada. É comum que estas cidades sejam extremamente especializadas no atendimento às demandas do agronegócio e que as funções voltadas a tais necessidades tenham primazia sobre as demais funções. Razão pela qual as chamamos metaforicamente de cidades do agronegócio, com o objetivo de evidenciar o poder das corporações do setor em impor seus interesses à economia e à (re)produção de seu espaço.

Dessa maneira, estabelece-se, de forma muito clara, o que Santos (1993) chamava da produção de espaços corporativos. Nas cidades do agronegócio, a produção do espaço corporativo por parte das empresas hegemônicas do setor é mais visível e deletéria, o que pode ser evidenciado com a análise das inúmeras e complexas desigualdades socioespaciais nelas difundidas. ${ }^{6}$

As cidades médias destacam-se nesta rede de cidades especialmente como centro de gestão de amplas regiões produtivas

\footnotetext{
6 A noção de cidade do agronegócio tem sido discutida desde a elaboração da minha tese de doutorado, defendida em 1996 no Programa de Pós-Graduação em Geografia da Universidade de São Paulo (USP), e posteriormente publicada pela EDUSP, em 2003, e reimpressa pela mesma editora em 2018. Sobre o tema, ver Elias (2003, 2007, 2010, 2016). Sobre as desigualdades socioespaciais nas cidades associadas ao agronegócio, ver Elias (2003a, 2006) e Elias e Pequeno $(2007,2015,2018)$.
} 
A Região Metropolitana como recorte espacial para estudos sobre o agronegócio... Denise Elias

do agronegócio, como já foi evidenciado em outros estudos ${ }^{7}$ As metrópoles globais, por sua vez, são o lugar do comando deste agronegócio. De maneira geral, é onde estão localizadas as sedes corporativas dos principais agentes do setor, tais como as corporações agroalimentares, as representações dos fundos do agronegócio, as principais empresas do sistema financeiro, os escritórios das bolsas de valores e mercadorias, as empresas de logística, entre outros.

Isto nos leva a relembrar e reforçar outras ideias já defendidas, como, por exemplo, a de que o agronegócio globalizado compõe o circuito superior da economia urbana de algumas das principais metrópoles do mundo (ELIAS, 2003a, 2017a).

Mais uma vez utilizando e adaptando os estudos de Santos (1993) para o tema presente, diríamos que enquanto as cidades médias e pequenas consolidam-se como lugares do fazer do agronegócio globalizado, os lugares do mandar são as metrópoles ou cidades globais onde se dá seu comando geral. São estas últimas que estão no topo da hierarquia da rede de cidades associadas ao agronegócio, assim como de resto para muitas outras atividades.

Exemplifiquemos para reforçar nosso argumento. Para tanto, nos valemos da localização das sedes corporativas das 50 principais empresas e corporações monopolistas do agronegócio com atuação no país, tendo como fonte de dados a edição especial da revista Exame - Melhores \& Maiores, as 1.000 maiores empresas do Brasil, de julho 2016.8

Das 50 maiores empresas/corporações associadas ao agronegócio, com controle acionário brasileiro e estrangeiro, 31 (62\%) tinham sede em metrópoles. A cidade de São Paulo era o grande destaque, pois concentrava 25 (50\%) das sedes corporativas de tais empresas, configurando-se, assim, como o epicentro do comando

\footnotetext{
7 Nos estudos de Elias (2003a, 2006, 2011, 2013a, 2015, 2017b) e Elias e Pequeno (2006, 2010, 2015) fica evidente o papel das cidades de porte médio como centros de gestão do que chamamos de região produtiva do agronegócio.

$8 \mathrm{Na}$ edição, há um levantamento das 400 maiores empresas do agronegócio por vendas líquidas.
} 
A Região Metropolitana como recorte espacial para estudos sobre o agronegócio... Denise Elias

do agronegócio no país, muito embora naturalmente seja somente um elo subalterno na rede de comando de tais corporações. ${ }^{9}$

Na mesma linha de exemplificação, os estudos já realizados e associados à pesquisa ora relatada nos permitem apontar alguns elementos de comprovação das três hipóteses aqui trabalhadas. Podemos utilizar dados da agroindústria alimentar, uma das principais atividades associadas ao agronegócio no Ceará, uma vez que algumas ocupam lugares de destaque nos principais rankings nacionais de seus respectivos segmentos, tais como de moinhos de trigo, laticínios e envasamento de água de coco.

Utilizando como variáveis o número de estabelecimentos da agroindústria alimentar e o número estabelecimentos com mais de 500 empregos, é possível construir um indicador referente ao que seriam os grandes estabelecimentos do ramo. Verifica-se que do contingente total das agroindústrias alimentares, 17 tinham acima de 500 empregos em 2016. Deste total, 15 possuíam tanto sedes corporativas como estabelecimentos industriais em apenas quatro cidades da RMF (Fortaleza, Maracanaú, Eusébio e Aquiraz). A cidade de Fortaleza sozinha reunia nove agroindústrias alimentares deste total de $15 .{ }^{10}$ Mesmo as duas corporações que não tinham seus estabelecimentos industriais na RMF possuíam sedes corporativas na cidade de Fortaleza.

Para encerrarmos esta seção, gostaríamos de citar Santos (1988, 1993), que ainda na década de 1980, referindo-se à realidade brasileira como um todo, dizia que não era mais possível utilizarmo-nos dos esquemas clássicos de hierarquia urbana para compreender o país. O mesmo vale para o caso das cidades que compõem a rede associada ao agronegócio.

O agronegócio se realiza totalmente a partir da dialética entre a ordem global e a ordem local, formando verdadeiras redes de produção e de poder globalizadas. Desse modo, para entender es-

9 Entre as 25 corporações com as respectivas sedes no Brasil localizadas na metrópole paulistana estão algumas das mais importantes do agronegócio do mundo, atuantes em diversos segmentos. As outras metrópoles eram Porto Alegre, Curitiba, Rio de Janeiro, Salvador e Cuiabá, cada qual com uma empresa; exceto Porto Alegre, com duas empresas.

10 Maracanaú possui três estabelecimentos da agroindústria alimentar com mais de 500 empregos; Eusébio possui dois e Aquiraz um. 
A Região Metropolitana como recorte espacial para estudos sobre o agronegócio... Denise Elias

sas redes é necessário considerar as relações com o espaço mais imediato, bem como as múltiplas e complexas relações interescalares.

Não é incomum, por exemplo, que as cidades do agronegócio estejam conectadas diretamente com as cidades globais, seja no Brasil ou em outras partes do mundo, e que não tenham nenhuma relação com algumas das cidades próximas. Isto é tanto mais verdadeiro quanto mais acirrada for a reestruturação produtiva da agropecuária e a divisão social e territorial do trabalho do agronegócio. Assim, para melhor compreender as interações espaciais entre as cidades que de alguma forma participam da economia e do território do agronegócio globalizado, é fundamental ter como princípio a heterarquia urbana. ${ }^{11}$

\section{Estratégias de operacionalização da pesquisa}

Partimos da compreensão de que para a realização de uma pesquisa científica é necessário combinar problemas de método e de metodologia aplicados ao estudo da economia política do território escolhido para estudo, no caso a RMF. Esta é estudada como uma fração do espaço total do planeta, cada vez mais aberta às influências exógenas e aos novos pilares do presente, tais como a reestruturação produtiva, o neoliberalismo e a financeirização (SANTOS, 1988; HARVEY, 2003; SOJA, 1993; ANTUNES, 2001).

Para Santos (1996), a pesquisa geográfica deve considerar o atual período histórico como um sistema temporal coerente, cuja explicação exige que se considere as características dos sistemas técnicos e dos sistemas de ação. Os primeiros nos dão a expansão da materialidade, dos fixos, e os segundos nos dão as bases históricas que promovem sua realização. Da mesma forma, devemos considerar também os fundamentos socioeconômicos e políticos, ou seja, os fatos da organização e controle em escala global que

$\overline{11 \text { Ver Catelan (2014). }}$ 
A Região Metropolitana como recorte espacial para estudos sobre o agronegócio... Denise Elias

têm a intermediação do Estado, que viabiliza a construção das bases técnicas demandadas pela globalização do espaço da RMF.

Com o objetivo de melhor explicitar como estamos operacionalizando a pesquisa, destacamos que, de maneira geral, foram adotadas duas estratégias: 1) composição de um conjunto de questões norteadoras; 2) confecção da matriz metodológica da pesquisa. A primeira serve como guia para a realização da pesquisa. São muitas as questões norteadoras que podem ser arroladas na busca da compreensão da economia política dos territórios do agronegócio, especialmente nas áreas que passam por processo recente de reestruturação econômica e territorial, como é o caso da RMF. ${ }^{12}$ A segunda é uma importante estratégia de operacionalização da pesquisa e objetiva organizar, logo no seu início, de maneira encadeada, os principais procedimentos de método e metodologia. ${ }^{13}$

É importante destacar que algumas das questões são recorrentes para os estudos sobre o agronegócio, independentemente do recorte espacial. Mas outras são bastante específicas para o caso da RMF, talvez extensiva a outras metrópoles. Elas são apresentadas aqui em toda sua complexidade para evidenciar os objetivos desta pesquisa e inspirar leitores a realizar novos estudos sobre o tema.

Em quais municípios da RMF existem atividades econômicas associadas ao agronegócio globalizado e em quais elas têm peso no cômputo total do PIB e na ocupação do espaço? Como a difusão do agronegócio está interferindo nas formas de uso e ocupação do espaço agrícola e urbano, nos regimes de propriedade da terra e na estrutura fundiária? Qual a importância da agroindústria alimentar no parque industrial da RMF, segundo o número de estabelecimentos e empregos? Qual a distribuição espacial da

\footnotetext{
12 Por vezes, por complexidades e especificidades que se mostram durante a realização da pesquisa, não é raro que algumas questões norteadoras acabem derivando para a organização de novas pesquisas, principalmente quando a pesquisa em realização tem objeto e objetivos ainda pouco trabalhados, como é o caso do agronegócio globalizado na RMF.

13 Os estudos sobre as formas de melhor organizar a metodologia de uma pesquisa científica, ao qual denominamos de matriz metodológica, foram inicialmente desenvolvidos durante colóquios promovidos entre 2003 e 2004 pelos membros do grupo de pesquisa Globalização, Agricultura e Urbanização (GLOBAU), coordenado por Denise Elias (UECE) e Renato Pequeno (UFC), por iniciativa do segundo pesquisador, durante o desenvolvimento da pesquisa intitulada Economia Política da Urbanização do Baixo Jaguaribe (CE), financiada pelo CNPq. Além dos professores-coordenadores, muitos orientandos e ex-orientandos utilizam a matriz metodológica no desenvolvimento de suas pesquisas.
} 
A Região Metropolitana como recorte espacial para estudos sobre o agronegócio... Denise Elias

agroindústria alimentar na RMF? É possível observar os processos de territorialização de empresas monopolistas agropecuárias e agroindustriais e a monopolização dos espaços agrícolas por estas empresas? Quais as interações espaciais entre as áreas de produção agropecuária e as agroindústrias presentes na RMF? Qual a importância do consumo produtivo do agronegócio (ELIAS, 2003, 2015) na economia urbana da RMF? É possível evidenciar nas cidades da RMF a participação de atividades do agronegócio no circuito superior da economia? Quais seriam as grandes empresas vinculadas ao agronegócio situadas na RMF? Qual a representatividade dos empregos do agronegócio no cômputo total dos empregos da RMF? Como evolui a taxa de urbanização dos municípios nos quais mais fortemente se processam transformações no espaço agrícola e urbano associados ao agronegócio? Quais respostas vêm sendo formuladas pelo Estado e pela sociedade civil organizada frente aos impactos socioespaciais de difusão do agronegócio? Existem redes de poder (sindicatos, entidades de classe etc.) associadas ao agronegócio na RMF? Quais demandas vêm sendo formuladas ao Estado pelas redes de poder do agronegócio? Qual o rebatimento do agronegócio no mercado de terras agrícolas e no mercado imobiliário no espaço interurbano na RMF? Alguma cidade da RMF assumiu novo papel na rede urbana do Ceará a partir da difusão do agronegócio nela realizado? Quais são as relações campo-cidade estabelecidas a partir da difusão do agronegócio na RMF? Há processos de concentração econômica e espacial na RMF associados ao agronegócio? Há mudanças na estruturação das cidades da RMF que podem ser associadas ao agronegócio? É possível observar processos de (re)estruturação urbano-regional na RMF associados ao agronegócio? Observa-se a entrada de grandes grupos econômicos (redes de hotéis, de fast food, franquias) que alteram as lógicas de estruturação dos espaços urbanos da RMF nas quais o agronegócio se destaca na economia? Onde se localizam os principais espaços de comando do agronegócio na RMF? Diante da inexistência do planejamento territorial metropolitano, qual é a importância de questões como a segurança hídrica, os conflitos 
A Região Metropolitana como recorte espacial para estudos sobre o agronegócio... Denise Elias

territoriais, a valorização imobiliária e a segregação espacial frente à presença do agronegócio na RMF?

$\mathrm{Na}$ sequência, apresentamos a matriz metodológica. É composta de temas, processos, agentes, variáveis e/ou indicadores e suas respectivas fontes de comprovação. ${ }^{14}$ Sua principal função é servir como um condutor para a operacionalização da pesquisa e considera questões de método e metodologia, da organização de seu banco de dados à redação final do trabalho. ${ }^{15}$

Os temas refletem os pilares teórico-conceituais adotados para a pesquisa, formando um conjunto de conceitos e noções. Para cada tema, são selecionados os principais processos associados para análise. Para cada processo são levantados os principais agentes envolvidos. Da mesma forma, para cada processo é selecionado algum dado para avaliar ou medir a evolução do que está sendo estudado, tal como uma variável e/ou indicador. ${ }^{16}$ Esses podem ser dados quantitativos ou qualitativos, primários ou secundários, mas devem possibilitar observar a evolução do que se tem como objetivo avaliar. Já para cada variável e seus respectivos indicadores operacionais é preciso haver ao menos uma fonte de comprovação, ou seja, a indicação da existência, de como e onde a informação será obtida, tais como as bases de dados fornecidas por instituições públicas (Instituto Brasileiro de Geografia e Estatística - IBGE, Instituto de Pesquisa Econômica Aplicada - IPEA, Agência Nacional de Águas - ANA, Ministério do Trabalho e Emprego - MTE, Instituto de Pesquisa e Estratégia Econômica do Ceará - IPECE, entre outros), as associações privadas (juntas comerciais, federações da indústria etc.), os resultados obtidos através de survey, as constatações a partir de trabalho de campo, a pesquisa documental e as entrevistas realizadas com atores de destaque, entre outros.

\footnotetext{
14 Para alguns casos, os agentes podem ser as próprias variáveis para compreensão dos processos.

15 Um banco de dados da pesquisa reúne um conjunto de informações levantadas e organizadas de uma pesquisa científica, desde as referências bibliográficas até os materiais de várias naturezas coletados durante trabalhos de campo e visitas técnicas. Em nada se assemelham com a organização de dados estatísticos, embora estes com grande frequência também façam parte do banco de dados de pesquisa.

16 É possível que uma variável permita a construção de diferentes indicadores e que eles correspondam a formas de operacionalização do estudo dos processos.
} 
A Região Metropolitana como recorte espacial para estudos sobre o agronegócio... Denise Elias

Cabe aqui um alerta importante: a utilização da matriz metodológica não pode ser utilizada como uma "camisa de força", ela deve ser flexível. Todo conhecimento adquirido para a consecução da pesquisa e os processos emergentes captados durante a análise de objeto de estudo devem contribuir para ultrapassar o discurso e a própria matriz pensados no início da pesquisa e, efetivamente, colaborar para o aperfeiçoamento dos instrumentos de realização da pesquisa, assim como de análise, inclusive incorporando fundamentos teórico-conceituais complementares.

Embora seja imprescindível organizar as questões de método e metodologia para iniciar uma pesquisa científica, essa organização pode sofrer mudanças, pois ela deve se ajustar à realidade estudada, permitindo a inserção de aspectos até então não considerados. Assim, é comum que no fim da pesquisa a matriz metodológica esteja reformulada, com novos processos, agentes, variáveis e indicadores. Entendemos que assim é possível avançar em direção a uma construção metodológica e teórica mais consistente.

Neste sentido, na seção a seguir apresentaremos cada um dos principais temas norteadores desta pesquisa, assim como os respectivos processos, agentes, variáveis e/ou indicadores e fontes de comprovação da matriz metodológica de nossa pesquisa sobre o agronegócio na RMF.

\section{Matriz Metodológica}

A matriz metodológica da nossa pesquisa sobre a RMF está ancorada em três temas principais: 1) a reestruturação produtiva da agropecuária; 2) a agroindústria alimentar e 3) o consumo produtivo do agronegócio. Antes de apresentá-los, vale destacar que a totalidade é indissociável, mas as subdivisões constituem um recurso metodológico importante, sem o qual dificilmente conseguiríamos efetivamente realizar a pesquisa. 
A Região Metropolitana como recorte espacial para estudos sobre o agronegócio... Denise Elias

Iniciemos com a reestruturação produtiva da agropecuária. ${ }^{17}$ Inúmeros intelectuais, tais como Santos (2000), Harvey (2003), Antunes (2001), destacaram que o atual período histórico está apoiado no tripé destrutivo baseado na reestruturação produtiva, no neoliberalismo, sob o comando do capital financeiro. Em outras oportunidades chamamos a atenção para o fato de que é neste mesmo tripé que estão ancoradas as metamorfoses da atividade agropecuária brasileira das últimas décadas, as quais culminam no que há cerca de 20 anos se convencionou chamar de agronegócio, a face da agropecuária sob o domínio do capitalismo monopolista, que já ocupa parte significativa das terras no país.

A reestruturação produtiva da agropecuária tem entre os seus objetivos minimizar uma das principais limitações para a acumulação ampliada do capital do setor, isto é, o tempo de produção sempre muito superior ao tempo de trabalho. Com a adoção de pacotes tecnológicos ${ }^{18}$ fortemente alicerçados na ciência, tecnologia e informação, transformaram-se as forças produtivas do setor, através de significativa modificação dos sistemas técnicos agrícolas e a difusão de um padrão estandardizado de produção, com aumento da produtividade e da produção (ELIAS, 2003, 2013b).

Isso possibilitou a ocupação mais intensiva da terra, mesmo daquelas que até então se mostravam pouco propícias à realização da atividade agropecuária em moldes do capitalismo monopolista, mas que com as novas forças produtivas se tornam passíveis de serem transformadas em prol das formas de produção em expansão. Desde então, promove-se uma verdadeira apropriação da natureza pelos principais agentes do agronegócio globalizado, tais como as corporações agroindustriais, agroquímicas, as tradings e os fundos de investimentos. ${ }^{19}$ De acordo com Martins (1980) ainda nos anos 1980, tal processo transforma a terra de trabalho, cada vez mais, em terra de negócios. Os impactos sociais, ambientais e

\footnotetext{
17 Entendemos que esse tema é recorrente para qualquer estudo sobre o agronegócio globalizado no Brasil. 18 Conjunto de insumos químicos, máquinas, produtos e serviços especializados, entre muitos outros. 19 Tais como Bunge, Cargill, ADM, Nestle, Bayer, Basf Philip Morris, Souza Cruz, John Deere, entre tantas outras.
} 
A Região Metropolitana como recorte espacial para estudos sobre o agronegócio... Denise Elias

espaciais são de grande monta para toda a sociedade e o território brasileiros. $^{20}$

Além de Trotsky, vários autores evidenciaram que o capitalismo se expande de forma desigual e contraditória, portanto, o agronegócio não se difundiu por todo o território brasileiro, nem da mesma forma. Primeiramente, o agronegócio ocupou as terras e áreas mais favoráveis aos seus objetivos expansionistas, notadamente no que Santos $(1986,1993)$ chamou de Região Concentrada. Mas desde a década de 1990, se difunde por áreas que até então funcionavam como verdadeiros lugares de reserva (SANTOS, 1993; ELIAS, 2002b). Assim chegou também ao Ceará, que historicamente pouca importância tinha na divisão do trabalho agropecuário no Brasil.

São muitos os processos associados à reestruturação produtiva da agropecuária cearense. Citamos aqui aqueles que mais diretamente estão relacionados a nossa pesquisa: alterações das formas de uso e ocupação do espaço agrícola; transformações no efetivo dos rebanhos; modernização dos sistemas técnicos agrícolas; alterações da condição legal das terras; crescimento da agropecuária empresarial; modificações no perfil de pessoal ocupado na agropecuária; aumento das formas de sujeição formal do pequeno agricultor; nova dinâmica do mercado de terras, com a intensificação do valor de troca em detrimento do valor de uso; incremento da concentração fundiária; formação de redes políticas do agronegócio; ampliação da logística para o agronegócio; acirramento dos conflitos sociais no campo (ELIAS, 1999, 2002a, 2002b, 2003b, 2005 e ELIAS; PEQUENO, 2006, 2013).

É possível reconhecer como principais agentes da difusão do agronegócio no Ceará as empresas agropecuárias e agroindustriais, já se observando a formação de corporações monopolistas. Segundo Oliveira (2016), as empresas monopolistas controlam a produção e se articulam através de dois processos monopolistas territoriais no comando da produção agropecuária. O primeiro é

20 Considerando os objetivos deste artigo, é inviável dissertar longamente sobre o agronegócio globalizado. Contudo, já o fizemos em outros estudos, ver Elias (2003a, 2013b, 2017a). 
A Região Metropolitana como recorte espacial para estudos sobre o agronegócio... Denise Elias

a territorialização dos monopólios, ou seja, quando as empresas atuam no controle da propriedade privada da terra, no processo produtivo no campo e no processamento industrial da produção agropecuária. O segundo é a monopolização do território, isto é, quando as empresas controlam camponeses e capitalistas produtores agropecuários através de mecanismos de subordinação, caracterizando a transferência de lucros e renda da terra; o que do ponto de vista de Martins (1981) é uma sujeição formal do camponês ao capital.

Quanto às variáveis e/ou indicadores associados aos processos supracitados, podemos citar: número e área dos estabelecimentos agropecuários segundo classes de utilização da terra (lavouras permanentes e temporárias, matas e florestas nativas, matas e florestas plantadas, pastagens naturais, pastagens plantadas, terras em descanso/produtivas não utilizadas, terras inapropriadas); efetivo dos rebanhos (bovinos, caprinos e ovinos, galináceos, produção de ovos, produção de leite); estabelecimentos que utilizam máquinas e implementos agrícolas; área agrícola irrigada; estabelecimentos/ área com acesso à eletrificação; estabelecimentos que utilizam insumos químicos e sementes selecionadas; estabelecimentos que utilizam agrotóxicos; quantidade de agrotóxicos utilizados nos estabelecimentos agropecuários; condição legal das terras (próprias, sem titulação definitiva, arrendadas, parceria, ocupadas); número de empresas agrícolas; pessoal ocupado e empregos formais em estabelecimentos agropecuários; preço da terra; estabelecimentos e área, segundo classes de área dos estabelecimentos agropecuários; instituições e órgãos ligados ao agronegócio; infraestrutura de logística; número de armazéns e silos.

No que tange às fontes de comprovação, teríamos de forma muito especial os Censos Agropecuários, a Produção Agrícola Municipal, a Produção Pecuária Municipal, o Abate, Leite, Produção de Ovos de Galinha (POG), todos produzidos pelo IBGE; a Relação Anual de Informações Sociais (RAIS) do Ministério do Trabalho e Emprego. Além destas fontes oficiais, teríamos ainda informações advindas dos trabalhos de campo, visitas técnicas às secretarias 
A Região Metropolitana como recorte espacial para estudos sobre o agronegócio... Denise Elias

municipais e estaduais, além de documentos organizados na hemeroteca. Para os dados do IBGE, os anos trabalhados são 1985, 1996, 2006 e 2017.

O segundo tema principal é o da agroindústria alimentar. Em nossa compreensão, o estudo da agroindústria alimentar é central para parte significativa dos estudos sobre o agronegócio no Brasil de uma maneira geral e para o Ceará de forma especial. Considerando seu caráter polissêmico, esclarecemos que por agroindústria consideramos as atividades industriais de beneficiamento, processamento ou de transformação de produtos originários da agropecuária, ou seja, as indústrias de transformação que têm suas matérias-primas oriundas da atividade agropecuária. Por agroindústria alimentar entendemos as indústrias que produzem toda uma extensa gama de alimentos processados ou matérias-primas e insumos para um numeroso conjunto destes alimentos.

As duas últimas décadas foram de grande crescimento para o setor, que se destaca no quadro geral da indústria de transformação (em número de estabelecimentos e de empregos), nos processos de territorialização dos monopólios no espaço agrário cearense e na monopolização de partes significativas dos territórios e da produção agropecuários, como já se observa, por exemplo, na cajucultura, na avicultura, na pecuária leiteira e na produção de coco.

Esse tema tem em seu âmago uma clássica característica da expansão do capitalismo no campo: a subordinação crescente da agropecuária à indústria (KAUTSKY, 1980). Isto se dá de diferentes formas, desde a dependência como consumidora de uma série de produtos industrializados (máquinas agrícolas, fertilizantes, agrotóxicos, sementes geneticamente modificadas etc.) até a entrega de parte cada vez maior da produção agropecuária à indústria para beneficiamento, processamento ou transformação. Para esta segunda situação, nosso interesse principal na pesquisa, citando Oliveira (2010), é quando teríamos a circulação subordinada à produção ou o monopólio na produção (agroindústria). 
A Região Metropolitana como recorte espacial para estudos sobre o agronegócio... Denise Elias

A magnitude deste processo pode ser observada, entre outros, pela própria transformação dos hábitos alimentares, especialmente desde os anos de 1970, com a criação de muitas novas mercadorias, todas provenientes da agroindústria alimentar, ou seja, alimentos refinados e processados em diferentes níveis, com adição de conservantes, aromatizantes, açúcares, tais como: embutidos; enlatados; congelados; sucos e refrigerantes; molhos prontos; massas alimentícias, biscoitos e salgadinhos; produtos derivados de leite; gelatinas; refrescos em pó; achocolatados; pães de forma; cereais matinais; óleo de soja; massas para bolo; alimentos instantâneos; carnes em conservas; temperos prontos; margarinas; sorvetes, muitos sem nenhum ou com baixíssimo valor nutricional. Tais mudanças impactam negativamente no bem-estar das pessoas e promovem inúmeros problemas à população, favorecendo o desenvolvimento de doenças crônicas não transmissíveis, algumas das quais hoje se constituem em verdadeiros problemas de saúde pública. ${ }^{21}$

Como toda mercadoria, desde então, os alimentos de uma maneira geral e os processados de forma especial passam a valer mais pela sua marca do que propriamente pelo seu valor nutricional, criando-se vários mitos para sustentar tal realidade. Ou será que existe alguma outra explicação para que uma mãe saudável substitua a amamentação pelo leite em pó? Aliás, não por coincidência, hoje o leite produzido no Brasil é um dos produtos de origem animal monopolizado pelo capital agroindustrial, ou seja, no qual há forte sujeição dos produtores aos interesses do capital industrial. 22

Para selecionarmos as agroindústrias de interesse para a pesquisa no quadro geral da indústria de transformação, utilizamo-

\footnotetext{
21 A obesidade, o diabetes, a hipertensão, as doenças cardiovasculares, a síndrome metabólica, o câncer de mama e outros tumores, a asma, o infarto, o acidente vascular cerebral estão entre as doenças associadas ao consumo de alimentos processados e ultraprocessados.

22 Associado ao padrão da alimentação corrente, temos novas formas de distribuição dos alimentos, comandadas pelas grandes redes de supermercados, que se transformaram nos principais centros de distribuição varejistas dos alimentos processados. A distribuição dos alimentos também corresponde a uma importante atividade que integra a complexa rede composta pelo agronegócio e que ainda necessita de estudos para melhor compreender o funcionamento das principais corporações do ramo e principalmente suas estratégias espaciais.
} 
A Região Metropolitana como recorte espacial para estudos sobre o agronegócio... Denise Elias

-nos da Classificação Nacional de Atividades Econômicas (CNAE). ${ }^{23}$ Identificamos 16 grupos. A partir dos objetivos de nossa pesquisa e das características do agronegócio globalizado no Ceará, dividimos estes grupos em dois grandes ramos, a saber: agroindústria não alimentar e agroindústria alimentar. Este último é nosso objeto específico de interesse, seja pela importância que o mesmo tem no cômputo total da indústria de transformação no Ceará, seja porque a agroindústria alimentar associa-se diretamente à difusão do agronegócio no estado. Dos 16 grupos, nove estão associados a agroindústria alimentar, ${ }^{24}$ sendo que cada um se desdobra em várias classes, que somam 36 no total. ${ }^{25}$ São estas que diretamente interessam à pesquisa.

Selecionamos nove processos associados às agroindústrias alimentares como os primordiais a serem abordados: expansão do número de estabelecimentos; crescimento do número de empregos; diversificação das classes da agroindústria alimentar; ampliação da concentração econômica; formação de corporações agroindustriais alimentares; incremento do poder econômico e político das corporações agroindustriais alimentares; concentração espacial das corporações agroindustriais alimentares; monopolização da produção agropecuária pelas corporações agroindustriais alimentares; aumento das relações campo-cidade promovidas pelas corporações agroindustriais alimentares.

Como principais agentes da expansão da agroindústria alimentar, temos importantes corporações em parceria com o estado em seus diferentes níveis, especialmente federal e estadual. Algumas destas corporações têm destaque não só no Ceará, mas em todo o país nos respectivos segmentos que representam.

\footnotetext{
23 "A CNAE é o instrumento de padronização nacional dos códigos de atividade econômica e dos critérios de enquadramento utilizados pelos diversos órgãos da Administração Tributária do país. Trata-se de um detalhamento da CNAE - Classificação Nacional de Atividades Econômicas, aplicada a todos os agentes econômicos que estão engajados na produção de bens e serviços, podendo compreender estabelecimentos de empresas privadas ou públicas, estabelecimentos agrícolas, organismos públicos e privados, instituições sem fins lucrativos e agentes autônomos (pessoa física)" (BRASIL, 2014).

24 São eles: Fabricação de bebidas; Processamento, preservação e produção de conservas de frutas, legumes e outros vegetais; Moagem, fabricação de produtos amiláceos e de rações balanceadas para animais; Abate e preparação de produtos de carne e de pescado; Laticínios; Torrefação e moagem de café; Produção de óleos e gorduras vegetais e animais e, finalmente, Fabricação de outros produtos alimentícios.

25 Dado a limitação de páginas do presente artigo, optamos por não as listar.
} 
A Região Metropolitana como recorte espacial para estudos sobre o agronegócio... Denise Elias

Quanto às variáveis e aos indicadores para avaliar os processos citados, utilizamos: número de estabelecimentos agroindustriais; número de empregos agroindustriais; número de empregos e estabelecimentos, segundo grupos e classes da agroindústria; número de empregos por estabelecimento segundo faixas de número de empregos; número de empresas com mais de 500 empregados; distribuição espacial dos estabelecimentos e dos empregos da agroindústria; localização da sede corporativa das agroindústrias alimentares; percentual de domínio da produção agropecuária por parte das agroindústrias; fluxos de trabalhadores, matérias-primas e insumos realizados entre o local da produção agropecuária e as sedes das agroindústrias alimentares.

Como fonte de dados termos a Relação Anual de Informações Sociais (RAIS), notadamente o número de estabelecimentos e empregos segundo seus diferentes desdobramentos, e os anos considerados são 1996, 2006 e 2016; a Federação da Indústria do Estado do Ceará (FIEC); documentos organizados na hemeroteca, especialmente notícias e matérias dos principais jornais diários, locais e nacionais; visitas técnicas às secretarias e agências de desenvolvimento do estado; rankings das principais empresas do país publicados por revistas de circulação nacional (por exemplo, Exame, Valor 1000, Globo Rural, Dinheiro Rural). Além disso, nos trabalhos de campo, em especial nas visitas técnicas às empresas agroindustriais, às entidades sindicais e às organizações não governamentais, é possível obter parte das informações que venham a confirmar ou a confrontar os processos sob investigação previamente apontados. ${ }^{26}$

Chegamos ao nosso terceiro e último tema adotado para caracterização do agronegócio na RMF, o consumo produtivo. A importância deste tema se deve a alguns fatores, como a já destacada subordinação crescente da agropecuária à indústria, o que tornou a primeira na condição de dependente da segunda, como consumidora de uma série de produtos industrializados, o que alterou radicalmente suas forças produtivas. Da mesma forma,

26 Em Elias (2003a, 113-185) dedicamos um longo capítulo ao estudo da agroindústria numa das principais regiões produtivas do agronegócio do Brasil, a de Ribeirão Preto (SP). 
A Região Metropolitana como recorte espacial para estudos sobre o agronegócio... Denise Elias

interligadas a esta e outras mudanças, são criadas várias demandas ainda mais complexas, seja de produtos ou serviços especializados, muitos até então inexistentes, mas que crescem de forma exponencial nas últimas décadas.

Os estudos sobre o consumo produtivo aparecem primeiro em Marx (1982), associados à reprodução dos meios de produção. Para o caso do agronegócio, é bastante explícita a relação com o processo de produção. Desde o início de nossos estudos para a realização do doutorado, na década de 1980, entendemos tal tema como estruturante para melhor compreender a difusão do agronegócio, assim como alguns dos mais importantes processos econômicos e espaciais a ele associados.

Naquela época, o termo consumo produtivo agrícola era discutido com base em Santos $(1988,1993)$. Porém, posteriormente optamos por consumo produtivo do agronegócio, visando deixar evidente a qual atividade agropecuária exatamente nos referíamos. Como o próprio nome explicita, este tipo de consumo está diretamente associado às condições gerais de produção do agronegócio, ou seja, aquele inerente à reprodução dos meios de produção (bens e serviços) para a consecução do agronegócio.

Assim, nos lugares onde se processam a reestruturação produtiva da agropecuária e a difusão do agronegócio globalizado, é recorrente que as cidades desenvolvam novas funções, ou seja, que expandam suas economias urbanas associadas ao consumo produtivo do agronegócio. ${ }^{27}$ Isto reforça nossa tese da crucial importância que a cidade e a economia urbana têm para a reprodução do capital do agronegócio.

Defendemos, desde então, que o crescimento destes comércios e serviços está entre os vetores de incremento não só da economia urbana, mas também como fator causal da (re)estruturação de várias cidades, de muitas novas relações campo-cidade, do incremento da urbanização, assim como de processos de (re)

27 Em algumas de nossas pesquisas consideramos o consumo produtivo do agronegócio em diferentes partes do país. Poderíamos citar Elias (2003a, 2009, 2015) e Elias e Pequeno (2010). 
A Região Metropolitana como recorte espacial para estudos sobre o agronegócio... Denise Elias

estruturação urbano-regional em regiões onde o agronegócio é relevante na economia e na produção do espaço.

No que diz respeito aos processos associados ao consumo produtivo do agronegócio, destacaríamos especialmente o crescimento da busca por bens e serviços especializados associados às condições gerais de produção deste. Efetivamente a lista destes bens e serviços se desdobra numa gama considerável. No referente às variáveis e aos indicadores, passaríamos para a indicação das principais adotadas para evidenciar tal processo. Começaríamos com as inerentes aos produtos: estabelecimentos comerciais de máquinas e equipamentos agrícolas, agrotóxicos, adubos, fertilizantes, corretivos do solo, sementes melhoradas, rações e produtos veterinários em especial. Muitas são as possibilidades de operacionalizá-las de modo a construir indicadores.

Quanto aos serviços, a lista é bem maior e a complexidade superior. Destacamos as que tomamos para nossa pesquisa: aluguel de máquinas; instituições de ensino superior, técnico e tecnológico com cursos voltados para o agronegócio, assim como seus respectivos cursos; empresas de transporte marítimo de cargas; empresas de transporte aéreo de cargas; serviços de armazenagem; empresas de pesquisa agropecuária; serviço de aviação agrícola; feiras agropecuárias; escritórios de exportação; serviço de consultoria (financeira, gestão, comércio exterior, planejamento, fusões e aquisições, vendas, irrigação, topografia, meio ambiente, principalmente) e serviços de aviação agrícola.

Sempre que existirem as informações, interessa-nos o número de estabelecimentos e de empregos associados a cada uma destas atividades, assim como a sua localização. Quando possível, temos como objetivo saber outras informações. Entre as que mais nos interessam está o destino destes comércios e serviços a partir da RMF, intentando detectar o alcance territorial de atuação das empresas, sejam elas comerciais ou de prestação de serviço, visando aferir as interações espaciais a partir da cidade de Fortaleza no oferecimento de comércios e serviços associados ao consumo produtivo do agronegócio. 
A Região Metropolitana como recorte espacial para estudos sobre o agronegócio... Denise Elias

Sobre as principais fontes de dados teríamos: dados da RAIS; MEC/Inep; Ceará Portos; Docas do Ceará; Pesquisa de Estoques IBGE; jornais de circulação diária com acesso via internet; trabaIhos de campo e visitas técnicas às empresas de desenvolvimento do estado do Ceará, sindicatos patronais, feiras agropecuárias, entre outros.

Vale destacar que dentre os temas trabalhados, este é o de maior complexidade para obtenção dos dados, especialmente no que tange aos serviços, seja pela quantidade, especialização ou mesmo falta de fontes, sendo que para obtenção de várias delas necessita-se de um trabalho bem mais minucioso e demorado de coleta e organização de dados primários. Quase como montar um patchwork com um conjunto de informações dispersas e sem uma fonte oficial para a sua obtenção, sem a possibilidade de construir séries históricas, ou seja, dependemos muito de informações documentais, das próprias empresas que prestam os serviços, de pessoas que atuam no ramo e de trabalhos de campo.

\section{Considerações finais}

O ineditismo de uma pesquisa sobre o agronegócio globalizado tendo como recorte espacial uma região metropolitana vem representado um desafio para sua realização, que exige do pesquisador uma visão transversal do conhecimento e uma compreensão cada vez mais dialética e holística da realidade.

Este trabalho pode funcionar como uma primeira pesquisa "guarda-chuva" com potencial para se desdobrar em outros estudos sobre os processos econômicos e espaciais que se mostrarem de maior repercussão. Estamos convictos de que muitas ideias de pesquisa surgirão e que são os primeiros passos para a efetivação de uma linha de pesquisa. Salientamos que as questões de método e de metodologia aqui trabalhadas, com ajustes, servem para outros recortes espaciais. 
A Região Metropolitana como recorte espacial para estudos sobre o agronegócio... Denise Elias

Para alguns aspectos considerados para análise, a pesquisa em andamento se apresenta como um estudo exploratório, no sentido que poderá oferecer visões gerais de determinados processos ainda pouco trabalhados da realidade de Fortaleza e respectiva região metropolitana.

Nossa principal meta quando do início da pesquisa era estudar o agronegócio na RMF. Mas, mesmo com a pesquisa ainda em desenvolvimento, estamos vislumbrando alguns resultados que não imaginávamos num primeiro momento, tal como a compreensão de que o agronegócio globalizado é fundamental para interpretar a própria economia política da cidade de Fortaleza e de sua região metropolitana. Com os próximos passos da pesquisa pensamos que será possível apresentar elementos de argumentação e comprovação desta afirmação que por ora fazemos como hipótese.

\section{Referências}

antunes, R. Os sentidos do trabalho. São Paulo: Boitempo, 2001.

Catelan, M. Heterarquia urbana. São Paulo: Cultura Acadêmica, 2014. CORRÊA, R. L. Processos, formas e interações espacials. Revista Brasileira de Geografia, Rio de Janeiro, v. 61, N. 1, p. 127-134, Jan./Jun. 2016.

ELIAS, D. Agronegócio globalizado: do campo a metrópole. In: FERREIRA, A.; RUA, J.; Mattos, R. C. (ORg.). O espaço e a metropolização. Rıo de Janeiro: ConsequênCiA, 2017A. P. 487-509.

ELIAS, D. Construindo a Noção de Região PROdUtiva do agronegócIo. In: OLIVEIRA, H. C. M. DE; CALIXTO, M. J. M. S.; SOARES, B. R. (ORG.). Cidades médias e região. São Paulo: Cultura Acadêmica, 2017B. P. 19-56.

ELIAS, D. Agronegócio e reestruturação urbana e regional no Brasil. IN: BUHLER, E. A., GUIBERT, M.; OLIVEIRA, V. L. DE O. (ORG.). Agriculturas empresariais e Espaços rurais na globalização. Porto Alegre: Ed. UfRGS, 2016. P. 63-82. 
A Região Metropolitana como recorte espacial para estudos sobre o agronegócio... Denise Elias

ELIAS, D. Consumo produtivo em Regiões do Agronegócio do Brasil. In: BELLET, C.; MELAZZO, E. S.; SPOSITO, M. E. B.; LLOP, J. M. (ORG.). URBANIZACIÓN, PRODUCCIÓN Y CONSUMO EM CIUDADES MEDIAS/INTERMEDIAS. LLeIDA: Ed. Univ. DE LLeidA, 2015. P. 35-56.

ELIAS, D. ReGIÕES PRODUTIVAS do AGRONEGócIo. In: BERNARDES, J. A.; SILVA, C. A. dA; ARRUZZO, R. C. (Org.). Espaço e energia. Rio de Janeiro: LAMPARINA, 2013A. P. 201-220.

ELIAS, D. Globalização, agricultura e urbanização no Brasil. Acta

Geográfica, Boa Vista, Ed. Especial. Geografia Agrária, p. 13-32, 2013в.

elias, D. Agronegócio e Novas Regionalizações no Brasil. Revista

Brasileira de Estudos Urbanos e Regionais (ANPUR), v. 13, p. 153-170, 2011.

ELIAS, D. O BRASIL AGRÍCOLA COM ÁREAS URBANAS: A CIDADE DO AGRONEGóCIO. In: OLIVEIRA, J.A. Cidades brasileiras. Manaus: UFAM, 2010. P.147-164.

ELIAS, D. ReESTRUTURAÇÃo PRODUtIVA DA AGROPECUÁRIA E URBANIZAÇÃo DISPERSA No Brasil. In: SANFELIU, C. B.; SPOSITO, M. E. (Org.). Las ciudades MEDIAS O INTERMEDIAS EM UM MUNDO GLOBALIZADO. LLEIDA: EDICIONS DE LA UNIVERSITAT DE LLEIDA, 2009. p. 87-105.

ELIAS, D. Fronteiras em mutação no Brasil Agrícola. In: FELDMAN, Sarah; Fernandes, Ana (Org.). O urbano e o regional no Brasil CONTEMPORÂNEO: MUTAÇÕES, TENSÕES, DESAFIOS. SalvadoR: EduFBA, 2007. P. 135-151.

elias, D. Ensalos sobre os espaços agrícolas de exclusão. Revista Nera, Presidente Prudente, v. 1, N. 8, P. 29-51, 2006.

ELIAS, D. ReESTRUTURAÇÃO PRODUtIVA DA AGRICULTURA CEARENSE. IN: SILVA, J.B.; CAVALCANTE, T.; DANTAS, E. (Org.). Ceará: um Novo olhar GeOgráfico. Fortaleza: Ed. Demócrito Rocha, 2005. P. 429-446.

EliaS, D. Globalização e agricultura. São Paulo: Edusp, 2003a. 400 p.

Elias, D. Desigualdade e pobreza no espaço agrário Cearense. Mercator, FoRTALEZA, v. 2, N.3, P. 61-69, 2003в. 
A Região Metropolitana como recorte espacial para estudos sobre o agronegócio... Denise Elias

ELIAS, D. A MOdernização dA PRODUÇÃo AGROPECUÁRIA. IN: ELIAS, D. (ORG.). O novo espaço da produç̧̃o globalizada: Baixo Jaguaribe (Ce). Fortaleza: FUNECE, 2002A. P. 281-355.

ELIAS, D. INTEGRAÇÃO COMPETITIVA DO SEMIÁRIDO CEARENSE. IN: ELIAS, D.; FURTADO, J. L. S. (Org.). Modernização excLUdente. Fortaleza: Demócrito Rocha, 2002в. P.15-43.

ELIAS, D. A agropecuária do Estado do Ceará no contexto da globalização. In: AMORA, Z. B. (Org.). Ceará: enfoques geográficos. Fortaleza: FUnECE, 1999. P. 43-72.

ELIAS, D.; PEQUENO, R. REESTRUTURAÇ̃̃o PROdUtIVA E DO TERRIT́́RIO DE MOSSORÓ (RN). IN: ELIAS, D.; PEQUENO, R. (ORG.). TENDÊNCIAS DA URBANIZAÇÃO BRASILEIRA: NOVAS DINÂMICAS DE ESTRUTURAÇÃO URBANO-REGIONAL. Rio de Janeiro: Letra Capital, 2018. P. 59-100.

ELIAS, D.; PEQUENO, R. (RE)ESTRUTURAÇão URBANA E desigualdades SOCIOESPACIAIS EM REGIÃo E CIDADE DO AGRONEGóCIO. GEOGRAPHIA (UFF), RIO DE JANEIRO, V. 17 N. 35, P. 10-39, 2015.

ELIAS, D.; PEQUENO, R. ReESTRUTURAÇão EConÔMICA e NOVA ECONOMIA política da urbanização no Ceará. Mercator, Fortaleza, v. 12, N. 28, P. 95112, MAIO/AGO., 2013.

ELIAS, D.; PEQUENO, R. Desigualdades SOCIOESPACIAIS NAS CIDADES DO agronegócio. Revista Brasileira de Estudos Urbanos e Regionais (Anpur), V. 9, N.1, 25-39, 2007.

ELIAS, D.; PEQUenO, R. (Org.). Agronegócio e dinâmicas socioespacials no Nordeste. Fortaleza: BNB/Etene, 2006.

harVeY, D. Condição pós-moderna. 6. ed. São Paulo: Loyola, 2003.

KAUTSKY, K. A questão agrária. 3. ed. São Paulo: Proposta Editorial, 1980.

MARTINS, J. de S. Expropriação e violência. São Paulo: Hucitec, 1980.

MARTINS, J. de S. Os camponeses e a política no Brasil. Petrópolis: VOZES, 1981. 
A Região Metropolitana como recorte espacial para estudos sobre o agronegócio... Denise Elias

MARX, K. Introdução [À CRítica da Economia Política]. In: MARX, K. Contribuição para a crítica da economia política. São Paulo: Abril Cultural, 1982 [1859]. (Coleção Os Pensadores).

Oliveira, A. U. A mundialização da agricultura brasileira. São Paulo: IÃNDE EDITORIAL, 2016.

LiVEIRA, A. U. Agricultura e indústria no Brasil. Campo-Território, UBERLÂNDIA, v. 5, N.10, P. 5-64, 2010.

ReVISTA eXAME. Melhores e maiores. São Paulo: Ed. Abril, 2016.

SANTOS, Milton. O espaço dividido. 2. ed. São Paulo: Edusp, 2004.

Santos, Milton. Por uma outra globalização. Rio de Janeiro: Record, 2000.

Santos, Milton. A natureza do espaço. São Paulo: Hucitec, 1996.

Santos, Milton. A urbanização brasileira. São Paulo: Hucitec, 1993.

Santos, Milton. Metamorfoses do espaço habitado. São Paulo: Hucitec, 1988.

SANTOS, MILTON. CIRCUITOS ESPACIAIS DA PRODUÇÃO: UM COMENTÁRIO. IN: SOUZA, M. A. A. dE; SANTOS, M. (Org.). A Construção do ESPAÇo. SÃo PaUlo: Nobel, 1986.

SOJA, E. W. Geografias pós-modernas. Rio de Janeiro: Jorge Zahar Ed., 1993.

Bacharela e licenciada em Geografia e doutora em Geografia Humana (1996) pela Universidade de São Paulo e Pós-doutora pela Universidade Estadual Paulista. Atualmente é Professora do Programa de Pós Graduação em Geografia da Universidade Estadual do Ceará. Orcid: https://orcid.org/0000-0002-8384-0990

Recebido para publicação em 13 de maio de 2020 Aceito para a publicação em 5 de junho de 2020 Publicado em 16 de junho de 2020 